\title{
Strategi Marketing Komunikasi Forum Komik Bandung dalam Membangun Brand Awareness
}

\author{
Fauziah Dila Noviana ${ }^{1}$, Diny Fitriawati² \\ 1,2Fakultas Ilmu Komunikasi, Universitas Adhirajasa Reswara Sanjaya Bandung \\ 1fauzdila@gmail.com,_Diny.fitriawati@ars.ac.id
}

\begin{abstract}
ABSTRAK
Industri Komik merupakan bagian dari perkembangan industri kreatif di Indonesia. Kemunculan acara-acara komik lokal semakin sering dilakukan seperti yang di lakukan di Kota Bandung melalui event Pasar Komik Bandung (PAKOBAN). Diperlukan strategi komunikasi pemasaran yang tepat agar dapat dibangun brand awareness yang tinggi dari customer maupun target pasar event tersebut. Tujuan dari penelitian ini adalah untuk mengetahui strategi komunikasi pemasaran yang dilakukan oleh penyelenggara event pasar komik bandung dalam membangun brand awareness. Metode peelitian ini menggunakan pendekatan kualitatif dengan studi deskriptif. Teknik pengumpulan data dalam penelitian ini dilakukan dengan cara observasi ke lapangan dan wawancara semi terstruktur. Pendekatan penelitian ini dibangun dengan model bauran komunikasi pemasaran. Hasil penelitian ini menunjukkan bahwa penyelenggara event pasar komik bandung memilih tiga bauran pemasaran yang paling efektif dalam membangun brand awareness dari customer dan masyarakat yaitu Periklanan, Hubungan Masyarakat dan Publisitas, Pemasaran Online dan Media Sosial. Komunikasi pemasaran yang dilakukan oleh pihak penyelenggara event Pasar Komik Bandung (PAKOBAN) telah berhasil membangun brand awareness dari masyarakat terhadap event tersebut.
\end{abstract}

Kata Kunci : Strategi; Komunikasi; Pemasaran; Brand Awareness; Customer.

\begin{abstract}
Comic Industry is part of the development of creative industries in Indonesia. The emergence of local comic events is increasingly being done like happening in Bandung through the Bandung Comics Market (PAKOBAN). The right marketing communication strategy is needed in order to build a high brand awareness of the customer and the target market of the event. The purpose of this study was to determine the marketing communication strategy carried out by the Bandung comics market event organizers in building brand awareness. This research method uses a qualitative approach with descriptive. Data collection techniques in this study were carried out by observation in the field and semi-structured interviews. This research approach is built on the marketing communication mix model. The results of this study indicate that the organizers of the Bandung comic market event chose the three most effective marketing mixes in building brand awareness from customers and the public which is Advertising, Public Relations and Publicity, Online Marketing and Social Media. Marketing Communications successfully create brand awareness from people about event Bandung Comics Market (PAKOBAN).
\end{abstract}

Keywords : Strategy; Communications; Marketing; Brand Awareness; Customer

\section{PENDAHULUAN}

Salah satu upaya dalam membantu perkembangan industri komik di Indonesia adalah dengan melakukan acara-acara yang mampu menampung inovasi dan kreatifitas dari para kreator komik secara periodik dan juga mampu memberikan nilai jual terhadap kreatifitas mereka. Salah satunya adalah agenda Pasar Komik Bandung (PAKOBAN) yang telah berlangsung sejak tahun 2005 (Gegemania, 2016).

Acara Pasar Komik Bandung memiliki tujuan untuk dapat membantu para komikus untuk menunjukkan potensi mereka kepada elemen industri, baik itu dari penerbit, pembaca, hingga sesama teman kreator dan penggiat seni visual ini. Salah satu hal yang menyebabkan acara ini mampu bertahan adalah semakin meningkatnya brand awareness dari masyarakat 
terhadap perhelatan acara ini. Hal ini juga dapat dicapai dengan adanya strategi komunikasi pemasaran yang apik dari penyelenggara.

Namun, terdapat beberapa permasalahan yang timbul seiring berjalannya agenda tersebut. Daya tampung partisipan dalam acara setiap tahunnya selalu terbatas dalam masalah kapasitas. Sedangkan jumlah pendaftar eksebisi selalu mengalami peningkatan dari tahun 2015 s.d 2019. Sehingga daya tampung acara tersebut tidak sebanding dengan kapasitas tempat acara.

Permasalahan tersebut mungkin saja terjadi terkait dengan adanya strategi komunikasi pemasaran yang kurang baik dalam menciptakan brand awareness terhadap event Pasar Komik Bandung. Hal ini terjadi ketika penyelenggara event tidak melakukan komunikasi mengenai jumlah kapasitas maksimal pendaftar yang dapat di ikutsertakan dalam acara.

Dampak komunikasi pemasaran sendiri adalah berkembangnya sebuah indsustri atau produk barang dan jasa yang akan dijual. Komunikasi pemasaran merupakan sebuah usaha untuk menyampaikan pesan kepada publik terutama konsumen mengenai keberadaan suatu produk/jasa di pasar.

Menurut Machfoedz, (2010) menyatakan bahwa komunikasi pemasaran adalah istilah yang digunakan untuk menerangkan arus informasi tentang produk dari pemasar sampai kepada konsumen. Pemasar menggunakan iklan, pemasaran langsung, publisitas, promosi penjualan, dan penjualan langsung untuk memberikan informasi yang mereka harapkan dapat mempengaruhi keputusan pembelian oleh konsumen, terutama dalam era yang serba menggunakan teknologi untuk membantu kegiatan pemasaran produknya.

Berjalannya Komunikasi Pemasaran yang kurang baik bisa berdampak pada lemahnya kesadaran merek (brand awareness). Brand Awareness atau kesadaran merek berangkat dari konsep mengenai brand equity. Aaker dalam Handayani, dkk., (2010), mendefinisikan kesadaran merek adalah kemampuan dari konsumen potensial untuk mengenali atau mengingat bahwa suatu merek termasuk kedalam kategori produk tertentu.

Terjadinya pembatasan peserta yang ada pada agenda PAKOBAN dapat berdampak pada turunya kesadaran merek dari para calon konsumen event tersebut, khususnya para kreator-kreator baru yang telah menunggu acara tersebut dilaksanakan satu tahun sekali. Menurut Durianto, (2004) Brand awareness adalah kesanggupan seorang calon pembeli untuk mengenali, mengingat kembali suatu merek sebagai bagian dari suatu kategori produk tertentu.

Untuk menghindari terjadinya penurunan kesadaran merek dari konsumen PAKOBAN, diperlukan strategi komunikasi pemasaran yang baik dari penyelenggara. Komunikasi pemasaran adalah cara yang digunakan perusahaan untuk menginformasikan, mempersuasi, dan mengingatkan konsumen, baik secara langsung maupun tidak langsung mengenai produk dan merek yang mereka jual. Komunikasi pemasaran berkontribusi terhadap ekuitas merek dengan membangun merek dalam ingatan (brand awareness) dan menciptakan citra merek (brand image) yang mencakup enam komponen yaitu periklanan, promosi penjualan, event, public relations dan publisitas, pemasaran langsung, dan penjualan personal (Kotler \& Keller, 2016). Tjahyono (2014) dalam penelitiannya menunjukkan bahwa semua tahapan strategi komunikasi pemasaran telah dilakukan oleh Marketing Communications Grand City Mall. Namun beberapa tahapan dilalui dengan strategi yang berbeda, seperti mengukur hasil promosi melalui pengamatan total traffic pengunjung dan feedback pengunjung event di sosial media. Selain itu, Marketing Communications juga tidak melakukan evaluasi event secara formal bersama seluruh anggota panitia. Hal tersebut dilakukan hanya dengan bertanya kepada beberapa anggota panitia apakah acara telah berjalan dengan baik. Artinya strategi komunikasi yang dilakukan belum mengaruh pada keinginan untuk membangun brand awareness yang tinggi. Selanjutnya Nur \& Firdaus, (2017) dalam penelitianya Strategi Komunikasi Pemasaran Batik Gonggong "Lawana" Tanjung Pinang dalam membangun Brand Awareness menyimpulkan bahwa terdapat tiga hal penting yang dilakukan dalam membangun brand awareness yaitu Segmentation, Targeting dan Positioning.

\section{Strategi}

Menurut Effendy (2007) Strategi pada hakikatnya adalah perencanaan (planning) dan manajemen (management) untuk mencapai sebuah tujuan. Pearce \& 
Robinson (2008) menjelaskan bahwa strategi adalah rencana berskala besar, dengan orientasi masa depan, guna berinteraksi dengan kondisi persaingan untuk mencapai tujuan. Menurut Cutlip \& Center, (2006) menjelaskan strategi mengacu pada keseluruhan konsep, pendekatan atau rencana umum untuk program yang dirancang untuk mencapai suatu tujuan.

\section{Komunikasi}

Menurut Hovland, Janis, dan Kelley (dalam Djuarsa, 2007) komunikasi merupakan suatu proses melalui seseorang (komunikator) dalam menyampaikan stimulus dengan tujuan mengubah atau membentuk perilaku orang lain. Menurut Effendy, (2003) komunikasi merupakan suatu upaya yang sistematis untuk merumuskan dengan cara yang setepat-tepatnya asas-asas pentransmisian informasi serta bentukan opini dan sikap.

\section{Strategi Pemasaran}

Menurut Chandra (dalam Wibowo, Arifin, \& Sunarti, 2015), strategi pemasaran merupakan rencana yang menjabarkan ekspektasi perusahaan akan dampak dari berbagai aktivitas atau program pemasaran terhadap permintaan produk atau lini produknya di pasar sasaran tertentu. Program pemasaran meliputi tindakan pemasaran yang dapat mempengaruhi permintaan terhadap produk, diantaranya dalam hal mengubah harga, memodifikasi kampanye iklan, merancang promosi khusus, menentukan pilihan saluran distribusi, dan sebagainya.

\section{Bauran Komunikasi Pemasaran}

Bauran komunikasi pemasaran menurut Kotler \& Keller, (2016) meliputi: Periklanan, Promosi Penjualan, Acara dan Pengalaman, Hubungan Masyarakat dan Publisitas, Pemasaran Online dan Media Sosial, Pemasaran Mobile, Pemasaran Langsung, Penjualan Personal. Lebih lanjut setiap bauran komunikasi pemasaran memiliki karakteristiknya masing-masing yang berguna untuk meningkatkan penjualan, menambah nilai produk dan jasa bagi konsumen, juga meningkatkan brand awareness konsumen.

\section{Brand Awareness}

David Aaker (dalam Handayani dkk., 2010) mendefinisikan brand awareness (kesadaran merek) adalah kemampuan dari konsumen untuk mengenali atau mengingat bahwa suatu merek termasuk kedalam kategori produk tertentu. Kesadaran merek atau brand awareness berarti kemampuan konsumen untuk dapat mengenali dan mengingat merek dalam situasi yg berbeda. Kesadaran merek terdiri dari brand recall dan brand recognition. Brand recall yaitu ketika konsumen melihat suatu produk yang ada didepan matanya maka mereka dapat mengingat produk itu dibuat dari brand mana, atau sederhananya kita dapat mengetahui nama merek setelah kita melihat suatu produk tertentu.

Berdasarkan paparan diatas maka fokus penelitian ini adalah untuk melakukan analisa deskriptif terhadap Komunikasi Pemasaran dari event Pasar Komik Bandung (PAKOBAN) dan Brand Awareness yang dihasilkan melalui strategi komunikasi pemasaran tersebut. adapun beberapa poin pertanyaan penelitian yang akan dibangun, diantaranya sebagai berikut:

1. Bagaimana penerapan strategi komunikasi pemasaran yang dilakukan oleh penyelenggara event Pasar Komik Bandung?

2. Bagaimana Brand Awareness yang dibangun oleh penyelenggara event Pasar Komik Bandung?

\section{METODE PENELITIAN}

Pendekatan kualitatif ialah pendekatan yang didalam usulan penelitian, proses, hipotesis, turun ke lapangan, analisis data dan kesimpulan data sampai dengan penulisannya 
mempergunakan aspek-aspek kecenderungan, non perhitungan numerik, situasional deskriptif, interview mendalam, dan analisis isi. Pendekatan kualitatif dipergunakan untuk menemukan atau mengembangkan teori yang sudah ada. Pendekatan kualitatif berusaha menjelaksan realitas dengan menggunakan penjelasan deskriptif dalam bentuk kalimat (Pujileksono, 2016). Metode penelitian dalam penelitian ini menggunakan studi deskriptif. Tujuan deskriptif adalah untuk melukiskan, memaparkan, atau menguraikan keadaan fenomena yang sudah dan sedang berlangsung (Gumilang, 2016). Deskripsi ialah menggambarkan secara jelas mengenai fenomena lapangan.

Peneliti menggunakan teknik sampling bertujuan/disengaja (purposive sampling) untuk menentukan subjek penelitian karena peneliti memerlukan data yang dapat menjawab semua pertanyaan penelitian dengan sesuai dan tepat. Seseorang atau sesuatu diambil/ditentukan sebagai sampel karena peneliti menganggap bahwa seseorang atau sesuatu tersebut memiliki dan dapat memberikan informasi yang diperlukan untuk kepentingan penelitiannya.

Objek penelitian ini adalah Forum Komik Bandung selaku penyelenggaran event Pasar Komik Bandung, objek penelitian ini dipilih secara purposive dengan pertimbangan informasi mengenai tata cara dan stretegi komunikasi pemasaran direncanakan dan direalisasikan oleh penyelenggara event Pasar Komik Bandung.

Teknik pengumpulan data yang peneliti gunakan selama penelitian ini, diantaranya, observasi lapangan (field observation) yang diartikan sebagai pengamatan dan pencatatan secara sistematik terhadap gejala yang tampak pada objek penelitian. Menurut Moleong, (2011) dan wawancara mendalam (intensive/depth interview) semi terstruktur, jenis wawancara ini sudah termasuk dalam kategori in-depth interview, di mana dalam pelaksanaannya lebih bebas bila dibandingkan dengan wawancara terstruktur. Teknik analisis data dengan menggunakan reduksi data, display data, kesimpulan dan verifikasi.

\section{HASIL DAN PEMBAHASAN}

\section{Komunikasi Pemasaran Event Pasar Komik Bandung dalam Membangun Brand Awareness}

Komunikasi Pemasaran event Pasar Komik Bandung dilakukan dengan berbagai metode pemasaran diantaranya Periklanan,, Hubungan Masyarakat dan Publisitas, Pemasaran Online dan Media Sosial.

Model Komunikasi pemasaran ini diimplementasikan sejak event Pakoban pertama kali diselenggarakan di tahun 2005. Peneliti menemukan bahwa strategi yang paling efektif untuk komunikasi pemasaran event Pakoban adalah melalui media periklanan dan hubungan masyarakat dan publisitas. Media periklanan yang dimaksud dalam hal ini adalah Kerjasama dengan media massa dan radio-radio di seluruh Indonesia. Peningkatan jumlah pendaftar merupakan bukti nyata keberhasilan dari event Pakoban dalam membangun komunikasi dengan calon customer mereka baik di sisi kreator-kreator komik lokal maupun masyarakat umum. Dalam menerapkan komunikasi pemasaran melalui hubungan masyarakat dan publisitas penyelenggaran event Pasar Komik Bandung berhasil melakukan kerjasama dengan dengan beberapa komunitas-komunitas pecinta komik di Indonesia seperti Komikara, Komunitas Bandung Strip Art yang berdiri di tahun 2015 sampai dengan Forum Komik di dalam lingkungan Universtitas seperti Pasukan Komik Maranatha (PAKOMAR) serta banyak lagi komunitas lainnya.

Data peningkatan partisipan terlihat dari data yang diberikan oleh penyelenggara dimana jumlah pendaftar dari tahun 2015-2019 selalu mengalami peningkatan yang stabil:

\begin{tabular}{|l|r|r|}
\hline \multicolumn{1}{|c|}{ Agenda Eksebisi } & Tahun & \multicolumn{1}{|c|}{ Jumlah Pendaftar (Orang) } \\
\hline PAKOBAN 4 - 2015 & 2015 & 76 \\
\hline PAKOBAN 5 - 2016 & 2016 & 86 \\
\hline PAKOBAN 6 - 2017 & 2017 & 89 \\
\hline PAKOBAN 7 - 2018 & 2018 & 94 \\
\hline
\end{tabular}


Hal ini menunjukkan bahwa antusiasme masyarakat khususnya para pecinta komik dari sisi kreator-kreator komik lokal semakin meningkat setiap tahunnya. Hal ini tentu berdampak positif bagi pengembangan event Pasar Komik Bandung.

Hasil penelitian menemukan keberhasilan penyelenggara dalam meningkatkan antusiasme tersebut adalah melalui tambahan efek penggunaan media sosial dan pemasaran online juga turut memberikan kontribusi pada perkembangan brand awareness event Pasar Komik Bandung. Kerjasama penggunaan media online diantaranya adalah promosi event melalui kerjasama dengan website ayobandung.com dan wisatabdg.com sebagai dua website yang terkenal akan pembagian informasi mengenai acara dan keunikan-keunikan ciri khas Kota Bandung.

\section{SIMPULAN \\ Simpulan} berikut:

Berdasarkan gambaran hasil penelitian, kesimpulan yang dapat diambil adalah sebagai

1. Dalam Strategi Komunikasi Pemasaran, penyelenggara event Pasar Komik Bandung (PAKOBAN) telah memilih bauran komunikasi pemasaran yang paling efektif yaitu Periklanan, Hubungan Masyarakat dan Publisitas, serta Pemasaran Online dan Media Sosial. Hal ini disebabkan bauran pemasaran yang menjadi pusat perhatian penyelenggara event Pasar Komik Bandung ditinjau dengan memperhatikan bahwa event komik masih memiliki keterbatasan dalam membuka segmentasi peminatnya.

2. Secara keseluruhan peneliti melihat bahwa Brand Awareness yang dibangun penyelenggara event Pasar Komik Bandung terhadap target pasar dan masyarakat telah cukup sukses dilakukan. Hal ini dikarenakan industri komik lokal sendiri baru berjalan sejak tahun 2000an, namun peningkatan perhatian masyarakat khususnya para kreator komik dan kesadaran terhadap penyelenggara event Pasar Komik Bandung sudah meningkat pesat selama tahun 2015-2019.

\section{Saran}

Peneliti menemukan bahwa salah satu hal yang perlu ditingkakan oleh penyelenggara event Pakoban adalah kapasitas tempat penyelenggaraan. Sejak Tahun 2005 penyelenggaran event Pasar Komik Bandung selalu dilakukan di Braga City Walk Mall Bandung dan dengan kapasitas yang terbatas oleh pengaturan pihak manajemen Mall Braga City Walk Bandung. Penyelenggara seharusnya dapat melakukan kerjasama dengan instansi pemerintahan khususnya Kementerian Pariwisata dan Ekonomi Kreatif sehingga penyelenggaraan event Pasar Komik Bandung dapat dilaksanakan dengan melibatkan unsur pemerintah sebagai pendukung pelaksanaannya pada industri kreatif di Indonesia.

Kerjasama ini diperlukan seiring dengan adanya target pemerintah Republik Indonesia dalam memberikan stimulus agar Industri Ekonomi Kreatif mampu berkembang di Indonesia.

\section{DAFTAR PUSTAKA}

Cutlip, S. M., \& Center, A. H. (2006). Effective Public Relations. Jakarta: Prenada Media.

Djuarsa, S. S. (2007). Teori Komunikasi. Jakarta: Universitas Terbuka.

Durianto, D. (2004). Strategi Menaklukkan Pasar Melalui Riset Ekuitas dan. Perilaku Merek. Jakarta: PT Gramedia Pustaka Utama.

Effendy, O. U. (2003). Ilmu, Teori dan Filsafat Komunikasi. Bandung: Citra Aditya.

Effendy, O. U. (2007). Ilmu Komunikasi Teori dan Praktek. Bandung: PT. Remaja Rosdakarya.

Gegemania. (2016). Latar Belakang Pasar Komik Bandung. Retrieved May 28, 2020, from https://laikdis.net/ website: https://laikdis.net/sejarah-pasar-komik-bandung/ 
Gumilang, G. S. (2016). Metode penelitian kualitatif dalam bidang bimbingan dan konseling. Jurnal Fokus Konseling, 2(2).

Handayani, D., Andrizal, Darmaja, A., Nasution, R. F., \& Ridwansyah, A. (2010). Brand Operation. Jakarta: ESENSI.

Kotler, P., \& Keller, K. L. (2016). Marketing Managemen (15th ed.). USA: Pearson Education, Inc.

Machfoedz, M. (2010). Komunikasi Pemasaran Modern. Cakra Ilmu: Yogyakarta.

Moleong, L. J. (2011). Metodologi Penelitian Kualitatif (Revisied). Jakarta: Remaja Rosda Karya.

Nur, A., \& Firdaus, M. (2017). Strategi Komunikasi Pemasaran Batik Gonggong "Lawana" Tanjungpinang dalam Membangun Brand Awareness. JOM FISIP, 5(1).

Pearce, J. A., \& Robinson, R. B. (2008). Manajemen Strategis- Formulasi, Implementasi dan Pengendalian. Jakarta: Salemba Empat.

Pujileksono, S. (2016). Metode Penelitian Komunikasi Kualitatif. Malang: Kelompok Intrans Publishing.

Tjahyono, N. (2014). Strategi Marketing Communications Grand City Mall Surabaya Dalam Membangun Brand Awareness Melalui Event Earth Hour 2013. Jurnal EKomunikasi, 2(1).

Wibowo, D. H., Arifin, Z., \& Sunarti. (2015). Analisis Strategi Pemasaran Untuk Meningkatkan Daya Saing UMKM. Jurnal Administrasi Bisnis, 29(1), 59-66. 